\title{
Assessment of drug use pattern for lower respiratory tract infection in outpatient department of paediatric at central referral hospital: a cross- sectional study
}

\author{
Chandrakala Sharma ${ }^{1}$, Arkojit Endow ${ }^{1}$, Sudip Dutta ${ }^{2 *}$
}

\begin{abstract}
${ }^{1}$ Department of Pharmacology,
${ }^{2}$ Department of Paediatrics,

Sikkim Manipal Institute of Medical Sciences, Sikkim, India
\end{abstract}

Received: 07 July 2017

Revised: 16 July 2017

Accepted: 29 August 2017

*Correspondence to:

Dr. Chandrakala Sharma,

Email:smimsck@gmail.com

Copyright: () the author(s), publisher and licensee Medip Academy. This is an openaccess article distributed under the terms of the Creative Commons Attribution NonCommercial License, which permits unrestricted noncommercial use, distribution, and reproduction in any medium, provided the original work is properly cited.

\begin{abstract}
Background: Prescription audit is an important tool to analyse rational use of drug at different health sectors. The aim of the study was to evaluate the prescribing pattern using World Health Organization prescribing indicators for lower respiratory tract infection in children below five years of age.

Methods: A cross-sectional study was conducted in the outpatient department of Paediatrics at Central Referral Hospital, Gangtok, Sikkim, India for a period of 18 months. Study involved children between 1-5 years of age with fever/cough with or without respiratory distress. The data were collected from the out patient department prescription slips as well as interviewing the parents/guardians after finishing the physician consultation. The data were processed using statistical software SPSS 20.

Results: The study was conducted with 57 prescriptions comprising 210 drugs from both male $(54.38 \%)$ and female $(45.61 \%)$ patients. The average number of drugs per prescription was found to be 3.68 . negligible $(0.013 \%)$ prescription containing generic name of drug was found, $96.66 \%$ of medicines were prescribed from National Essential List of Medicine (NELM). No prescriptions were found to have injectables, $8.57 \%$ of the prescriptions were found to contain fixed dose combination. Amongst the drug categories, salbutamol accounted for $23.33 \%$ in total prescription followed by paracetamol $(22.85 \%)$ and amoxicillin $(7.14 \%)$. While accounting for the formulations used, the maximum prescriptions were containing syrup followed by nebulization.

Conclusions: The use of generic names was minimal, only few of the prescriptions had vitamins and tonics with no use of injectable preparations. Maximum numbers of drugs were prescribed from NELM.
\end{abstract}

Keywords: Drug utilization, Indicators, Prescribing, Sikkim

\section{INTRODUCTION}

Irrationality in drug use is a global problem affecting both developed and developing countries. Sound knowledge on prescribing indicators and strict adherence to the World Health Organization's (WHO) rational drug use policy is considered to be the means of eliminating the deleterious effect of drugs to some extent. Risk of inappropriate drug utilization can be reduced through periodic educational intervention and proper monitoring at different health sectors.
Drug use in extremes of age is a common issue and studies have shown that $40 \%$ of Indian population is constituted by children. ${ }^{1}$ They are susceptible to recurrent infection of gastrointestinal and respiratory tract, accounting for the major portion of pediatrics visit. ${ }^{2}$ Globally, about two million children die due to acute respiratory infection, particularly Lower Respiratory Tract Infection (LRTI), at the age below five years. ${ }^{3}$ Children at the age group of 1-3 years are even more susceptible to infection, improper hygiene, diet and vaccination; hence more LRTI cases have been seen. ${ }^{4}$ 
While treating children for LRTI, wide ranges of drugs are used thus encountering various adverse effects. Studying drug use pattern will be of immense help for healthcare providers, stakeholders, policy makers, planners for the successful implementation of policies that have been formulated for the benefit of patient. The study will also help in preparing hospital formularies, local therapeutic guidelines for common diseases encountered in paediatric age group in the particular region. The data so obtained would help the physician in tailoring of medicine to a patient thereby improving the therapeutic benefit and reducing the economic burden arising due to inappropriate use of drug.

Sikkim is a small hilly state of India in the Eastern Himalayas and has a population of $6,07,688$, comprising 64111 children (32761 male and 31350 female) in the age group of 0-6 years with calculated sex ratio of $957.5 \mathrm{It}$ experiences the climate like extreme cold winter, high humidity during summer due to more rainy and cloudy days, probably most congenial for prevalence of diseases like LRTI. Occurrence of URI and LRTI are related to the climatic conditions, more prevalence is reported in cooler seasons of the year. ${ }^{6}$ Respiratory tract infection is caused both by viruses and bacteria. Viruses alone accounts for $30-67 \%$ of pneumonia occurring mostly in infants. ${ }^{7}$ Pneumococcal infection peaks usually during winter months which could be due to indoor crowding, cold weather, low humidity, associated viral infection. ${ }^{8}$ Therefore to relate such factors in this reason is equally important so that the prevention and treatment of the diseases can be made accordingly. There are study reports coming up pertaining to health issues of the adult from the state but there are rarely any studies concerning the health status of children and the type of drugs been used for the management of their diseases.

Moreover, in India very limited studies have been conducted to evaluate the prescribing pattern for respiratory tract infections in children which is otherwise the most common type of illness observed worldwide in children below five years of age. ${ }^{9}$ Keeping in view the mentioned facts, present study was envisaged to evaluate the prescribing pattern in the management of lower respiratory tract infections and to promote rational use of drugs with an ultimate goal to decrease the mortality due to common diseases in this vulnerable age group.

\section{METHODS}

A cross-sectional hospital based study was conducted in the Department of Paediatrics at Central Referral Hospital (CRH), Tadong, Sikkim, for a period of 18 months in the year 2014-15. The data so mentioned in this paper is a part of a dissertation work submitted for post graduate degree in pharmacology. Approval of the protocol from the Research Protocol Evaluation Committee (RPEC) and Institutional Ethics Committee (IEC) of Sikkim Manipal Institute of Medical Sciences, Gangtok, were sought prior to the commencement of the study. Prior written consent was taken from parent/guardian for this study. Verbal information was provided to each parent/ guardian stating the purpose of collection of information. Inclusion criteria for the study was decided to take the children with the age between 1-5 years, visiting outpatient department with fever/cough with or without respiratory distress. Children with congenital heart and lung diseases and the parents/guardians who were not willing to participate in the study were excluded from the study. The data were collected minimum of twice in a week from the O.P.D prescription slips and by interview of parent/guardian after finishing the physician consultation. Only one prescription per patient was included during the study period to avoid repetition of the same data. The data regarding gender, age, ethnicity, income, locality, birth history, immunization history, family history, duration of illness, provisional diagnosis, co-morbid condition/diseases were collected. Drug used data such as total number of drug used, number of drug prescribed per prescription, route of administration, drugs prescribed by generic names and brand name, drugs from NEML, FDC used, number of injectable preparations, formulations used, cost per prescription were noted. The data so collected were noted in a case record form devised for the study. Each recorded case was authenticated on a daily basis by researchers. Data were tabulated and analysed using SPSS 20.

\section{RESULTS}

A total of 57 prescriptions were collected during the entire study period. The gender distribution of the patients revealed that males $(n=31 ; 54.38 \%)$ outnumbered the females $(n=26 ; 45.61 \%)$. Observation on WHO prescribing indicators showed that average number of drugs per prescription were 3.68 and $75.43 \%$ prescription were found to contain four drugs per prescription. Only $0.013 \%$ of drugs were prescribed in generic name whereas $96.66 \%$ of medicines were prescribed from NELM. The prescriptions containing fixed dose combinations were $8.57 \%$ but none of the prescription were containing injectable preparations (Table 1).

Table 1: Prescribing indicators.

\begin{tabular}{|ll|}
\hline Indicators & Value \\
\hline Total no of drugs used for LRTI & 210 \\
\hline Average number of drugs per prescription & 3.68 \\
\hline $\begin{array}{l}\text { Total number of drugs prescribed by generic } \\
\text { name }\end{array}$ & 03 \\
\hline $\begin{array}{l}\text { Total number of prescriptions containing } \\
\text { generic names }\end{array}$ & 33 \\
\hline Total drugs from NELM & 203 \\
\hline Total number of FDC used & 18 \\
\hline Total number of injectable used & $\mathrm{Nil}$ \\
\hline Cost per prescription & 92 \\
\hline Total Prescriptions containing >1 antibiotics & 08 \\
\hline $\begin{array}{l}\text { Total number of prescriptions containing } \\
\text { Vitamins/tonics }\end{array}$ & 03 \\
\hline
\end{tabular}


Table 2: Gender wise distribution based on categories of drugs prescribed in total prescription.

\begin{tabular}{|c|c|c|c|c|c|c|}
\hline \multirow[b]{2}{*}{ Drug categories } & \multicolumn{2}{|c|}{ Male $(n=31)$} & \multicolumn{2}{|c|}{ Female (n=26) } & \multirow[b]{2}{*}{$\begin{array}{l}\text { Total } \\
\text { prescribed }\end{array}$} & \multirow[b]{2}{*}{$\begin{array}{l}\text { Total not } \\
\text { prescribed }\end{array}$} \\
\hline & Prescribed & $\begin{array}{l}\text { Not } \\
\text { prescribed }\end{array}$ & Prescribed & $\begin{array}{l}\text { Not } \\
\text { prescribed }\end{array}$ & & \\
\hline Antibiotics & 29 & 02 & 25 & 1 & 54 & 03 \\
\hline Antiallergics & 4 & 27 & 01 & 26 & 5 & 53 \\
\hline Bronchodilators & 28 & 02 & 23 & 03 & 51 & 05 \\
\hline Nasal drops & 03 & 28 & 4 & 22 & 07 & 50 \\
\hline Antipyretics & 24 & 07 & 24 & 02 & 48 & 09 \\
\hline Cough syrup & 11 & 20 & 3 & 23 & 14 & 43 \\
\hline MVI & 1 & 30 & 2 & 24 & 03 & 54 \\
\hline
\end{tabular}

Table 3: Distribution of number of drug prescribed from each categories and formulations used.

\begin{tabular}{|ll|llll|}
\hline Drugs Categories & Number of drugs = n $(\%)$ & Formulations used & Nebulize & Tablet \\
\hline Antibiotics & Syrup & Drop & Nebs & 01 \\
\hline Bronchodilators & $74(35.23 \%)$ & 73 & - & - & - \\
\hline Antipyretics & $58(27.61 \%)$ & 15 & - & 43 & - \\
\hline Cough syrups & $49(23.33 \%)$ & 48 & 01 & - & - \\
\hline Nasal Drops & $14(6.66 \%)$ & 14 & - & - & - \\
\hline Antiallergies & $07(3.33 \%)$ & - & 07 & - & - \\
\hline Tonics/Multivitamines & $05(2.38 \%)$ & 05 & - & - & - \\
\hline Total & $03(1.42 \%)$ & 02 & 01 & - & 01 \\
\hline
\end{tabular}

The prescriptions containing antibiotics were higher in number followed by bronchodilators and antipyretics, whereas fewer prescriptions were containing antiallergics, nasal drops and multivitamins (Table 2).

Among all the drugs, antibiotics (35.71\%) were prescribed the most whereas multivitamins, antiallergies and nasal drops were prescribed the least (Table 3).

Table 4 reveals the pattern of antibiotic prescription, Beta lactam group was most prescribed antibiotic, among which amoxicillin alone or in combinations was the highest. Azithromycin was prescribed in $9.04 \%$ of the cases. Salbutamol was the only bronchodilators and paracetamol, the only antipyretics prescribed. Cough syrup was prescribed in $6.66 \%$ of the total cases, amongst which broncho free syrup was prescribed in maximum. Otrinoz was prescribed in maximum prescription amongst the nasal drops whereas the prescription containing antiallergics and multivitamins were the least (Table 4). On studying the drug wise prescription pattern, Salbutamol (23.33\%) was followed by paracetamol $(22.85 \%)$ and amoxicillin (7.14\%) (Table 4). While accounting for the formulations used in the total prescriptions, all the nasal remedies were prescribed in drops whereas all the drugs from antiallergics, cough remedies, antibiotics, antipyretics, multivitamins were prescribed in syrup formulations except one prescription each from antibiotics, antipyretics and multivitamins were prescribed in tablet and drop formulations respectively. The bronchodilators were prescribed maximum in nebulize formulations (74.14\%) and others (25.86\%) in syrup formulation. Prescription with only salbutamol was found to be higher than Salbutamol and Ipratropium bromide combination.

\section{DISCUSSION}

Children below five years of age constitute the most vulnerable group to contract common illnesses. Effective therapy for such illnesses depends on the accurate diagnosis and appropriate and timely management of the disease to achieve rational and cost-effective therapy. Rationality in drug therapy depends on number of factors ranging from care providers to the receivers. WHO has laid down various indicators for measuring drug use in different settings and the data so obtained would help in generating the rationality in drug therapy. It is a matter of important concern that the data regarding the use of drug in paediatric age group is not well established. Moreover, the huge ranges of licensed drugs are not in appropriate doses forms for paediatrics use. The hospital based study would be one of best platform to gather data regarding such information. This type of study has not been conducted so far in the state. Therefore, the data so obtained would provide valuable insight into the drug use pattern in a paediatric department of a tertiary care hospital which would further, aid to offer information for such studies in larger population in future. 
Table 4: Distribution of drugs prescribed from individual classes.

\begin{tabular}{|ll|}
\hline Antibiotics & $\begin{array}{l}\text { Number of } \\
\text { drugs = n (\%) }\end{array}$ \\
\hline $\begin{array}{l}\text { Amoxicillin and clavulunic acid } \\
\text { combinations }\end{array}$ & $27(12.85 \%)$ \\
\hline Azithromycin & $19(9.04 \%)$ \\
\hline Amoxicillin & $15(7.14 \%)$ \\
\hline Cefpodoxime proxetil & $14(6.66 \%)$ \\
\hline Cefixime & $1(0.47 \%)$ \\
\hline Bronchodilators & \\
\hline Salbutamol & $49(23.33 \%)$ \\
\hline $\begin{array}{l}\text { Salbutamol and Ipratropium } \\
\text { Bromide }\end{array}$ & $5(2.38 \%)$ \\
\hline Levosalbutamol & $4(1.90 \%)$ \\
\hline Antipyretics & \\
\hline Paracetamol & $48(22.85 \%)$ \\
\hline Antiallergics & \\
\hline $\begin{array}{l}\text { Levocetrizine and montelukast } \\
\text { combination }\end{array}$ & $2(0.95 \%)$ \\
\hline Montelukast & $2(0.95 \%)$ \\
\hline Cetrizine & $1(0.47 \%)$ \\
\hline Cough Syrup & $1(0.47 \%)$ \\
\hline Bronchofree & $4(1.90 \%)$ \\
\hline Syp.Soventus & $3(1.42 \%)$ \\
\hline Syp.Ambrolite S & $3(1.42 \%)$ \\
\hline Syp.Kofarest & $2(0.95 \%)$ \\
\hline Syp.Dilo BM & $1(0.47 \%)$ \\
\hline Syp.Chericoff LS & $1(0.47 \%)$ \\
\hline Nasal Drops & \\
\hline Otrinoz & $5(2.38 \%)$ \\
\hline Otrivin mini & $1(0.47 \%)$ \\
\hline Otrivin S & $1(0.47 \%)$ \\
\hline Multivitamines/Tonics & $1(0.47 \%)$ \\
\hline Syp.Osteopolybion & $1(0.47 \%)$ \\
\hline Syp.Glory L & $1(0.47 \%)$ \\
\hline Drop Fortis B & \\
\hline & \\
\hline
\end{tabular}

The demographic profile in this study showed $54.38 \%$ male and $45.61 \%$ female, indicating more male patients approaching for physician consultation than female patients. This finding corroborates with the other Indian studies. ${ }^{10-12}$ The incidence of polypharmacy is common, as majority of prescription listed an average of three to four drugs. This led to decreased prescription adherence, drug interaction and chances of antibiotic resistance. The average number of drugs per encounter also indicates higher values than the recommended limit of 2.0. ${ }^{13}$ This result is in consistence to the study report of Murthy et al, but much higher than observation made by Karande et al, and less than other study. ${ }^{2,11,10}$ It is advisable to keep the average number of drug as low as possible as it is more economical and rational. The drugs prescribed from NELM were highly satisfactory but equally disappointing findings were seen in drugs prescribed by generic names. Prescription by brand names has become a trend which could be due to direct or indirect influence from pharmaceutical companies for promotional strategies that may hamper some of the important goals of essential drug list concept. No inclusion of injectables in prescriptions during the study contradicts some other studies. ${ }^{10,14}$ Inclusion of antibiotics in prescription corroborates the study of Najmi et al. ${ }^{14}$ In contrary to the reports in this study, the maximum number of prescriptions enlisting antipyretics followed by anti-infective agents was shown in a study in North India. ${ }^{10}$ The use of antibiotics in viral infection will unnecessarily incur exuberant cost of treatment, increases resistance. The treating physician must have rational in treatment by using appropriate therapy for the specific indication and for appropriate duration. Inhalational bronchodilators and antipyretics were the other group of drugs which was used in maximum number of prescription. The use of cough and cold remedies and multi vitamins were least as compared to previous study which might have been the reason for lesser cost of a prescription as compared to other studies. ${ }^{10,15}$

Maximum use of antibiotics, particularly, amoxicillin alone or in combination is in consistence to study in inpatient paediatric department by Vishwanath, et al. ${ }^{16}$ Use of salbutamol alone or in combination with ipratropium bromide corroborates the finding of Vishwanath, et al. ${ }^{16}$ Higher use of bronchodilators in outpatient department in this study asserts unspecified lower respiratory tract infection, some with pneumonia or bronchopneumonia or with RSV infection with or without respiratory distress. Paracetamol was the only antipyretic to be used in total prescription which is slightly differing from the study done by Vishwanath, et al, where they have noted the combination of paracetamol and ibuprofen (9.37\%) from total prescriptions. ${ }^{16}$

In contrary to the earlier reports, the present findings showed the maximum use of syrup formulation in total prescription followed by the nebulized forms and least use of drops and tablets. ${ }^{12,17,18}$ The use of liquid doses forms in out patients setting in paediatrics is an important contributing factor for medication error. ${ }^{19}$ The use of graduated caps or standard measuring methods should be advised to patient particularly in out patients settings if the drug are to be dispensed in liquid doses forms to minimize the medication error. Overall the observation on the listing of more than one antibiotic in a prescription was minimal in comparison to other studies but was in consistent to the observation made by Karande et al, where they have noted only three prescription containing two antibiotics out of 198 prescriptions with antibiotics. ${ }^{11,14,20}$ However, the representation on the use of antibiotic in this study is not an irrational one as the patient included in this study were with fever with or without respiratory distress which ultimately require at least one antibiotics for adequate management of the disease. The use of fixed dose combination was minimal. Among the combination therapy amoxicillin and clavullinic acid was used in maximum (12.85\%) prescription, but was less than the previous study report $(25.33 \%) .{ }^{14}$ Besides, the antibiotics, 
salbutamol and ipratropium bromide, montelukast and levocetrizine were the other combinations that were used in total prescriptions. The cost per prescription in this study was quite economical which is considered to be an important parameter for prescription adherence. The low cost per prescription could be due to the use of single antibiotic in maximum prescription, low use of multivitamins, cold and cough remedies as well as no use of injectable preparation. Study reviews have stated that the use of injectable preparation would increase the overall cost of a prescription that may predisposed to under treatment.

\section{CONCLUSION}

In conclusion, the study has highlighted some of the common prescribing pattern in Central Referral hospital. The maximum use of antibiotics, less use of generic name and polypharmacy were the characteristics patterns. The drug prescription pattern adhered to the rational prescribing practice were also observed, such as, no use of injectable, prescription from NELM, minimal use of vitamins and tonics.

\section{ACKNOWLEDGEMENTS}

Authors acknowledge the authority of Sikkim Manipal Institute of Medical Sciences, Gangtok for providing all the facilities for present studies. The guardians/ parents of the children patients are acknowledging herewith for responding the questionnaire.

Funding: No funding sources

Conflict of interest: None declared

Ethical approval: The study was approved by the Institutional Ethics Committee

\section{REFERENCES}

1. Ashraf H, Handa S, Khan NA. Prescribing pattern of drugs in outpatient department of child care centre in Moradabad city. International Journal of Pharmaceutical Science Review and Research. 2010;3(2):1-5.

2. Venkateswaramurthy N, Murali R, Sampathkumar R. The study of drug utilization pattern in pediatric patients. International Journal of Pharmacology and Pharmaceutical Science. 2013;5(3):140-4.

3. Islam F, Sarma R, Deboy A, Kar S, Pal R. Profiling Acute Respiratory Tract Infection in Children from Assam, India. Journal of Global Infectious Diseases. 2013;5(1):8-14.

4. Jhansi M, Kumar VS, Manigandan LS, Priyarajam V. Patterns of prescription and drug use in paediatric department of a lower respiratory tract infection at a teaching hospital: A preliminary study. Research Journal of Pharmaceutical, Biology and Chemical Science. 2015;6(2):1202-05.

5. India Census. Ministry of Home Affairs, Government of India; 2011. Available at: http://www.censusindia.gov.in/2011 common/census_ 2011.htm. Accessed 9 March 2016

6. Erling V, Jalil F, Hanson LA, Zaman S. The impact of climate on the prevalence of respiratory tract infection in early childhood in Lahore. Pakistan Journal of Public Health Medicine. 1999;21(3):331-9.

7. World health organization. Pneumonia (Fact Sheet), 2012. Available at: http://www.who.int/mediacentre/factsheets/en/.

Accessed 8 March 2016.

8. European Centre for Disease Prevention and Control. pneumococcal disease, 2011. Available at: http://www.ecdc.europa.eu/enhealthtopics/pneumoco ccal_infection/Pages/index.aspx. Accessed 8 March 2016.

9. Kamath KR, Feldman RA, Rao PS, Webb JK. Infection and disease in a group of South India families. II. General morbidity patterns in families and family members. American Journal of Epidemiology. 1969;89(4):375-83.

10. Akhtar MS, Vohora D, Pillai KK, Dubey K, Roy MS, Najmi AK, et al. Drug prescribing practice in Paediatric department of north Indian university teaching. Asian Journal of Pharmaceutical and Clinical Research. 2012;5:146-9.

11. Karande S, Sankhe P, Kulkarni M. Patterns of prescription and drug dispensing. Indian Journal of Pediatrics. 2005;72:117-21.

12. Dinesh KG, Padmasani L, Vasantha J, Veera RB, Sudhakar P, Uma MR. Drug prescribing pattern among pediatricians in an out-patient department of tertiary care teaching hospital. Indian J Pharm Pract. 2011 Apr;4(2):64-8.

13. International Network for Rational Use of Drugs and World Health Organization. How to investigate drug use in health facilities: Selected drug use indicators. EDM Research Series No. 7 [WHO/DAP/93.1]. Geneva: World Health Organization, 1993.

14. Najmi A, Verma A, Aiman U. Drug utilization study in the outpatient pediatric department of a tertiary care teaching hospital of district Lucknow. Asian Journal of Pharmaceutical and Clinical Research. 2015;8(3):327-30.

15. Tzimis L, Kafatos A. Drug utilization and nutrition patterns among children from indigent and emigrant families in Crete, Greece. Public Health. 2000;114:393-7.

16. Vishwanath M, Reddy S, Narayana, DS. Assessment of drug utilization in hospitalized children at a tertiary care teaching hospital. Journal of Chemistry and Pharmaceutical Research. 2014;6(2):592-8.

17. Thiruthopu NS, Mateti UV, Bairi R, Sivva D, Martha S. Drug utilization pattern in South Indian pediatric population: A prospective study. Perspective in Clinical Research. 2014;5(4):178-83.

18. Dimri S, Tiwari P, Basu S, Parmar VR. Drug use pattern in children at a teaching hospital. Indian Pediatrics. 2009;46:165-7.

19. Walsh KE, Kaushal R, Chessare JB. How to avoid pediatric medication errors: a user's guide to the 
literature. Archives of Diseases in Childhood. 2005;90:698-702.

20. Shamshy K, Begum M, Perumal P. Drug Utilization of Antimicrobial drug in Pediatrics Population in a tertiary care hospital in Erode, Tamil Nadu, India. International Journal of Pharm Tech Research. 2011;33:1530-36.
Cite this article as: Sharma C, Endow A, Dutta S. Assessment of drug use pattern for lower respiratory tract infection in outpatient department of paediatric at central referral hospital: a cross-sectional study. Int J Basic Clin Pharmacol 2017;6:2352-7. 